IP Periodica Polytechnica

Mechanical Engineering

57(1), pp. 27. 33 2013

DOI: 10.3311/PPme.7014

Creative Commons Attribution (i)

RESEARCH ARTICLE

\section{Thermal FE analysis of a one side brake block test equipment (Part 1)}

\author{
Gábor Fekete, Károly Váradi
}

Received 2013-05-30

\begin{abstract}
The present paper includes the first part of an investigation of the complex braking process during the braking of railway vehicles, using transient thermal FE models with temperature dependent material properties. In the development of the geometric model, efforts were made to take the test equipment into consideration to as great an extent as possible, enabling the investigation through time of the thermal behaviour of the entire apparatus. Bearing houses were modelled in a simplified manner and contact heat resistances were applied for bearings. $\mathrm{Nu}$ merical calculations were validated by measurement data. The correspondence of the results applying the two methods was acceptable.
\end{abstract}

\section{Keywords}

FEM $\cdot$ railway brake block test equipment $\cdot$ heat generation by friction $\cdot$ thermal contact resistance

\section{Acknowledgement}

The authors are grateful to Professor István Zobory for his valuable advices.This work is connected to the scientific program of the "Development of quality-oriented and harmonized $R+D+I$ strategy and functional model at BME" project. This project is supported by the New Hungary Development Plan (Project ID: TÁMOP-4.2.1/B-09/1/KMR-2010-0002).

\section{Gábor Fekete}

Department of Machine and Product Design, BME, H-1111 Múegyetem rkp. 3, Hungary

e-mail: fekete.gabor@gt3.bme.hu

\section{Károly Váradi}

Department of Machine and Product Design, BME, H-1111, Múegyetem rkp. 3, Hungary

e-mail: varadik@eik.bme.hu

\section{Introduction}

In addition to a precise description of friction conditions, it is essential to explore the (elastic and plastic) contact and thermal conditions of the brake block and the wheel rim in friction for the design and dimensioning of railway brake blocks. Braking characteristics depend on load, motion and material properties. By drawing on adequate information, braking friction and wear processes can be forecasted and the wear speed of the friction pair can be reduced, which is an important expectation in regard to the economy of railway operation. The complex phenomenon of braking was investigated through the analysis of a brake block test equipment operated at the Department of Railway Vehicles of Budapest University of Technology and Economics (BME). Research commenced by determining the thermal state of the equipment. The heat distribution of the equipment was determined by a thermal FE model in a steady state at a given braking power; in addition, transient tests were performed to track the process of heating up. In order to take heat conduction precisely into consideration, thermal contact resistances were applied inside the bearing boxes. A 3D model is required to be applied to model the actual heat-up process [1]. Calculation parameters were validated by temperature measurements. The CosmosWorks software was used for FE calculations; measurements were performed at BME Department of Railway Vehicles.

\section{Test equipment}

The testing equipment developed in the 1980's is suitable for examining the friction, heat and wear processes of a railway brake block vs. wheel rim on a scale of 1:4. Fig. 1 shows a photo about the test equipment.

Fig. 2 shows the dimensions of the brake block and the braked wheel.

\section{Material properties}

The brake block is made of P14 cast iron with high phosphorous content. The mechanical and thermal properties of this material in function of the temperature had been determined during the cooperation of the Department of Railway Vehicles of Budapest University of Technology and Economics (BME) and 


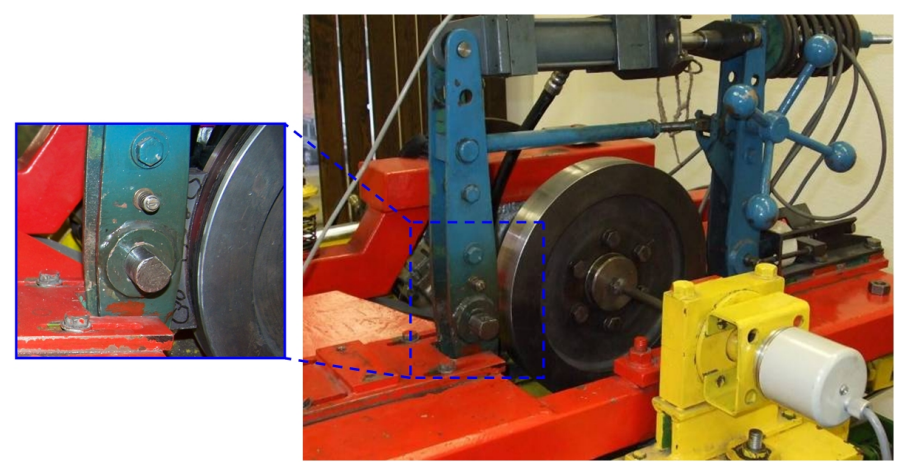

Fig. 1. Small sample test equipment with one side brake block configuration
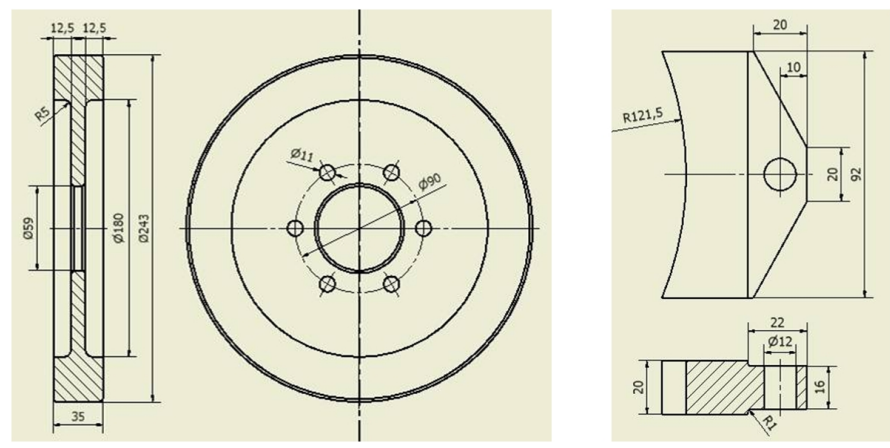

Fig. 2. Main dimensions of the test wheel and brake block (scale 1:4)

the TU Dresden Institut für Schienenfahrzeugtechnik. Fig. 3 shows the dependence of elastic modulus $E$ and linear thermal expansion coefficient $\alpha$ on temperature $t$. Fig. 3 . illustrates the dependence of specific heat $c$ and thermal conductivity $\lambda$ on temperature. Fig. 4. shows the changes of friction coefficient $\mu$ in the function of temperature. Poisson's ratio and density do not depend on the temperature, their values are as follows:

- Poisson's ratio: $v=0.25$,

- density: $\rho=7150 \mathrm{~kg} / \mathrm{m}^{3}$.

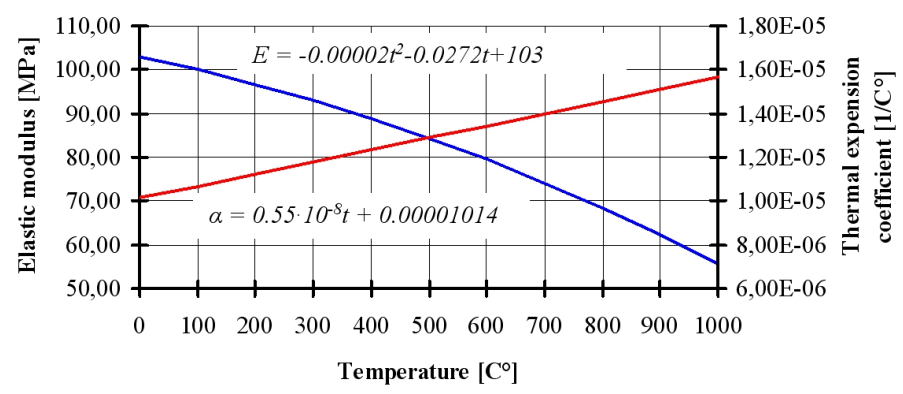

_ Elastic moduhs — Thermal expension coefficient

Fig. 3. Temperature dependence of elastic modulus and the thermal expansion coefficient of cast iron P14

The test wheel was made of carbon steel A38. Its material properties used for calculations are contained by Tab. 11 The materials of further components were defined with simplifications, namely that the material of all components was set as normal structural steel (Tab. 1).

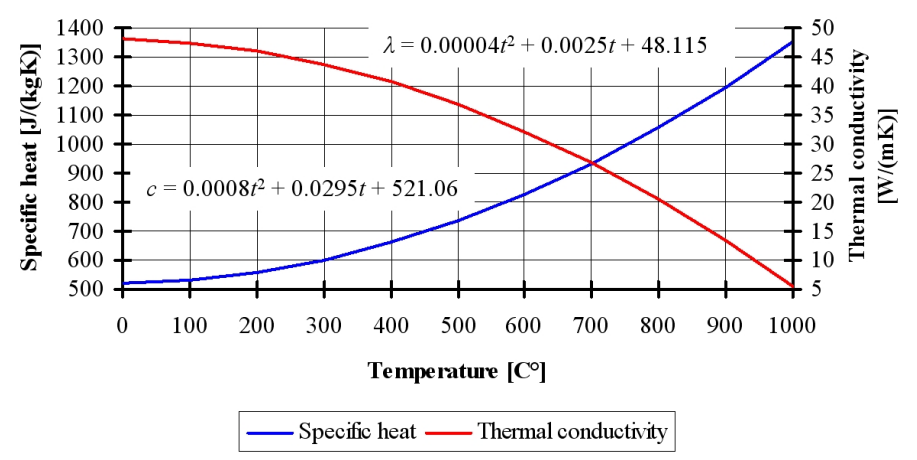

Fig. 4. Temperature dependence of elastic modulus and the thermal expansion coefficient of cast iron P14

\section{FE model of the testing equipment}

Fig. 5] shows the geometric model required for calculating the thermal state of the test equipment.

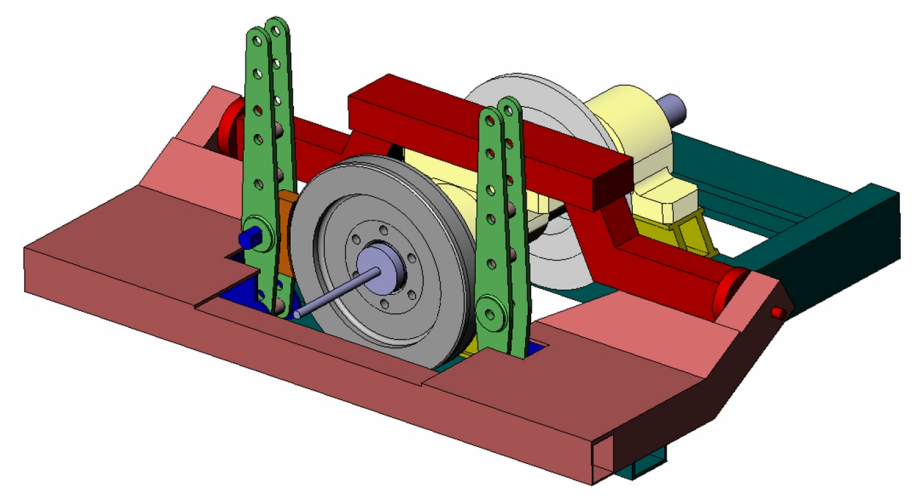

Fig. 5. Geometric model of the test equipment

The scope of the model was determined in a way that only those parts were removed from the testing equipment which do not heat up in a consolidated temperature state, either. As the measurement was validated by a single brake block design, the geometric model also contains only 1 brake block. The SKF SN 510 type bearing houses were taken into consideration with a simplified geometry, taking care of the fact that the size of heat convection surfaces and the mass of the bearing house should correspond to the respective characteristics of the actual bearing house. The heat insulation effects of bearings were taken into account with contact thermal resistances in the thermal model. Fig. 6, shows the armature taken out of the complete geometric model, together with the three bearing houses and the two brake block holders. The braked wheel in the test equipment is driven by a steel friction disk to model the contact between wheel and rail. The flat disk rotating in the middle of the shaft enables the investigation of disk brakes.

10-node second order tetrahedron elements were used in the FE model, with an average element size of $2 \mathrm{~mm}$ along surfaces in friction and $8 \mathrm{~mm}$ elsewhere. Fig. 7 shows the entire model examined and the FE mesh refinement on the surfaces in friction of the brake block and the wheel.

The thermal load of the FE model was determined based on the operating conditions of the test equipment. The total heat power generated in the course of braking $(Q)$ can be determined 
Tab. 1. Material properties of wheel and other components of the FEA model

\begin{tabular}{lcc}
\hline Material property & Values for A38 steel & Values for normal structural steel \\
\hline Elastic modulus & $200[\mathrm{GPa}]$ & $200[\mathrm{GPa}]$ \\
Poisson's ratio & 0.3 & 0.29 \\
Density & $7860\left[\mathrm{~kg} / \mathrm{m}^{3}\right]$ & $7900\left[\mathrm{~kg} / \mathrm{m}^{3}\right]$ \\
Thermal expansion coefficient & $1.5 \mathrm{e}-5\left[1 /{ }^{\circ} \mathrm{C}\right]$ & $1.5 \mathrm{e}-5\left[1 /{ }^{\circ} \mathrm{C}\right]$ \\
Thermal conductivity & $47[\mathrm{~W} /(\mathrm{mK})]$ & $47[\mathrm{~W} /(\mathrm{mK})]$ \\
Specific heat & $420[\mathrm{~J} /(\mathrm{kgK})]$ & $420[\mathrm{~J} /(\mathrm{kgK})]$ \\
\hline
\end{tabular}
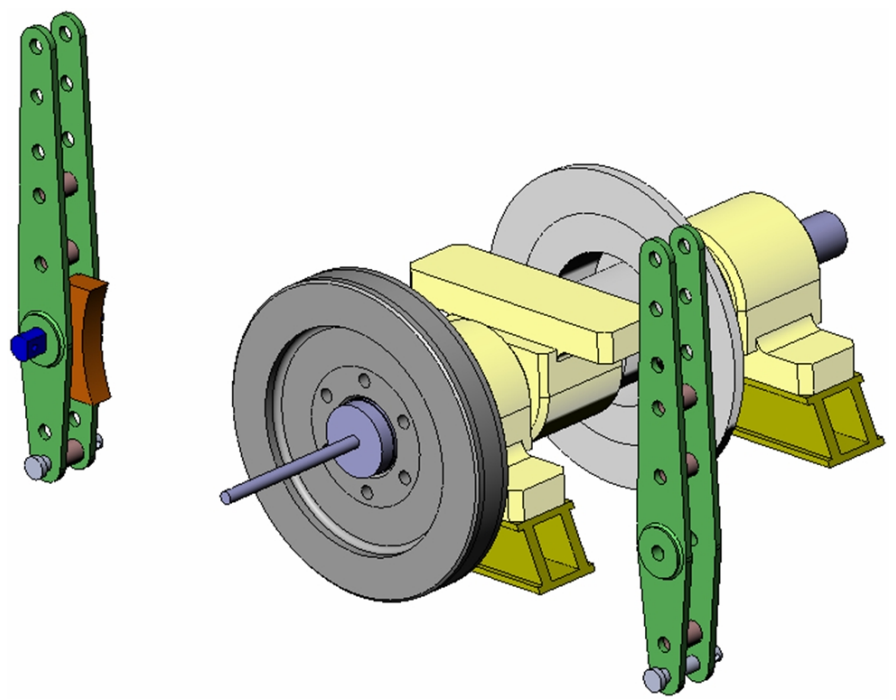

Fig. 6. Test equipment model with bearings and arms to hold brake block

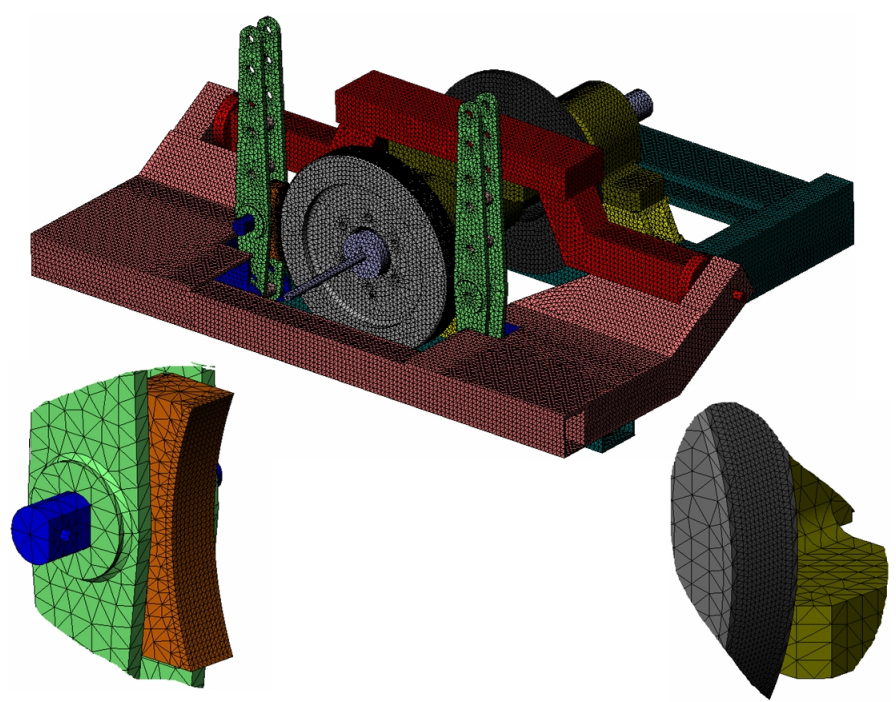

Fig. 7. FE mesh of the model subjected to the thermal analysis

by the following equation [2]

$$
Q=F_{S} v=F_{N} \mu v=p_{N} A_{S} \mu v,
$$

where $F_{N}$ is the normal force acting on the brake block; $F_{S}$ is the friction force generated on the brake block; $\mu$ is the average friction coefficient; $v$ is the average sliding speed; $A_{S}$ is the operating surface of the braking block; and $p_{N}$ is the average surface pressure. It was assumed that the $F_{N}$ and $\mu$ and also the sliding speed $(v)$, furthermore the $Q$ remain constant during the test process. Tab. 2 summarizes the operation conditions and the initial data associated therewith.

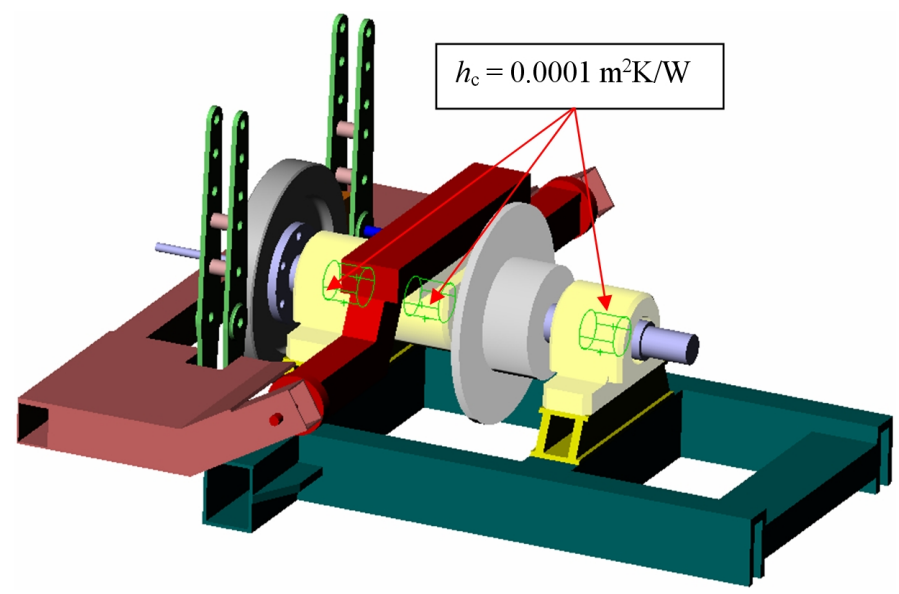

Fig. 8. Thermal contact resistances in the thermal model

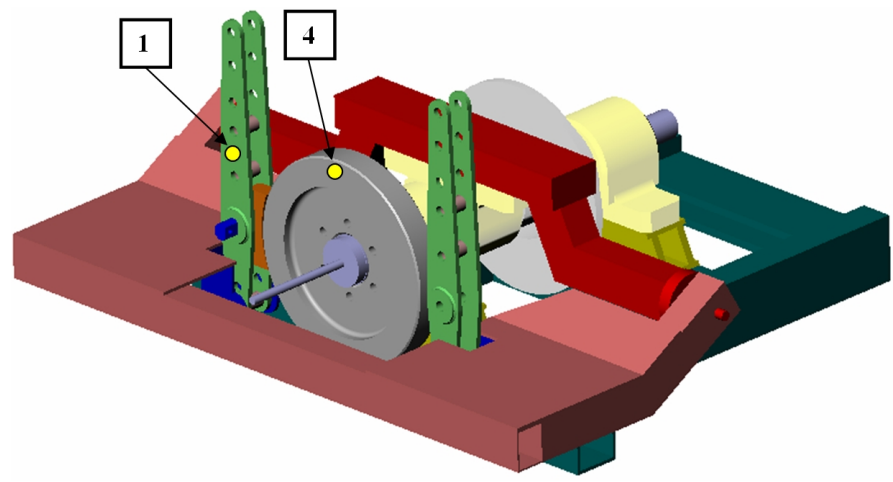

Fig. 9. Points of the temperature measurement on the model

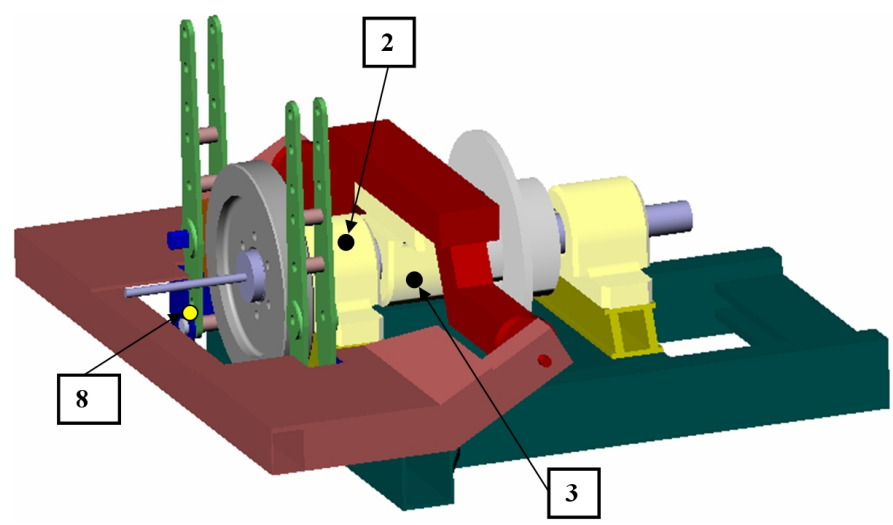

Fig. 10. Points of the temperature measurement on the model

Different values were set for the convective heat transfer coefficient $\alpha$ in case of stationary and rotating parts, respectively. For stationary structural parts and components,

$$
\alpha=5 \mathrm{~W} / \mathrm{m}^{2} \mathrm{~K},
$$



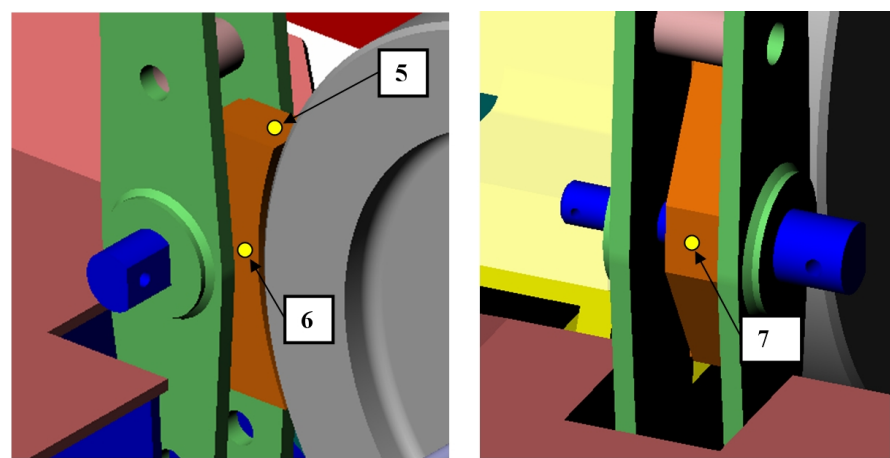

Fig. 11. Points of the temperature measurement on the model

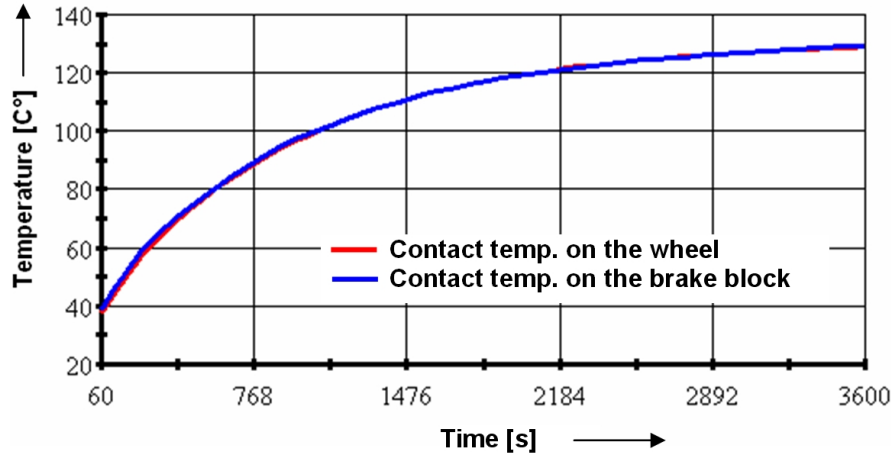

Fig. 12. Change of the maximum temperature of the contacted friction surfaces of the wheel and the brake block in function of the time

Tab. 2. Initial data and further calculated operation conditions

\begin{tabular}{lcc}
\hline Complete braking block surface & $A_{S}$ & $0.001884 \mathrm{~m}^{2}$ \\
Normal force acting on the brake block & $F_{N}$ & $100 \mathrm{~N}$ \\
Average surface pressure & $p_{N}$ & $0.053 \mathrm{MPa}$ \\
Average sliding speed & $v$ & $11.62 \mathrm{~m} / \mathrm{s}$ \\
Average friction coefficient & $\mu$ & 0.384 \\
Heat power & $Q$ & $446 \mathrm{~W}$ \\
Environment temperature & $T_{k}$ & $25^{\circ} \mathrm{C}$ \\
\hline
\end{tabular}

and for the rotating wheel,

- if diameter $D$ is

$D \leq 60 \mathrm{~mm}$ then $\alpha=5 \mathrm{~W} / \mathrm{m}^{2} \mathrm{~K}$,

- if diameter $D$ is $60<D \leq 120 \mathrm{~mm}$ then $\alpha=22 \mathrm{~W} / \mathrm{m}^{2} \mathrm{~K}$,

- if diameter $D$ is $120<D \leq 180 \mathrm{~mm}$ then $\alpha=25 \mathrm{~W} / \mathrm{m}^{2} \mathrm{~K}$,

- if diameter $D$ is $180<D \leq 250 \mathrm{~mm}$ then $\alpha=30 \mathrm{~W} / \mathrm{m}^{2} \mathrm{~K}$.

Rolling bearings constitute a significant obstacle in terms of thermal conductivity, and this may fundamentally influence the process of heating up and the heat distribution to be produced. The "heat insulation" impact of bearings, that is, contact heat transfer can be modelled by a fictitious convective heat transfer coefficient. The value of which in the thermal model was selected to be

$$
\alpha^{*}=10000 \mathrm{~W} / \mathrm{m}^{2} \mathrm{~K},
$$

[3]. In the CosmosWorks software, the inverse of contact heat transfer, the so-called thermal contact resistance must be specified:

$$
h_{C}=\frac{1}{\alpha^{*}}
$$

the value of which is: $h_{c}=0.0001 \mathrm{~m}^{2} \mathrm{~K} / \mathrm{W}$.
Tab. 3. Locations of the temperature measurement points

\section{Measurement / control point}

No. Description

1 On the external surface of the left arm to hold the brake block, between two screws

2 On the upper external mantle surface of the bearing box beside the braked wheel

3 On the external surface of the central bearing box, on the side of the bearing box

On the upper external front surface of the braked wheel

On the upper plate of the brake block

On the front plate of the brake block, in the centre

On the back side of the brake block

8 On the external surface of the left arm to hold the brake block, at the bottom

Fig. 8 shows the location of contact heat resistances in the thermal model.

\section{Location of measurement and control points in the model}

The results of numerical calculations were checked on the test equipment by temperature measurements. Measurement points were designated for controllability, where the calculated temperatures were checked by measurement. Figs. 9-11 illustrate and Tab. 3 summarizes the locations of the temperature measurement points.

\section{Transient calculations}

The model is "thermally loaded" by the friction energy (converted into heat power) generated at the points of contact of the brake block and the wheel. According to Tab. 2, the value thereof is $446 \mathrm{~W}$. The problem was solved by distributing the heat load by heat partitions, meaning that the total heat generated must be distributed between the brake block and the wheel so that the temperature of the surfaces in friction of the two components should be identical [4]. (In case of transient FEA calculations, this condition must be met at each iteration step.) In the FEA simulations the wheel was separately analyzed by using the distributing heat source model [5]. At the same time step the rest of the model formed a separate model, there was not any physical contact connection between the wheel and the brake block. For both models the heat power followed the given heat partitions to fulfil the contact temperature condition [4]. In calculations for a steady state, distribution of the total heat between the two components is the result of a calculation of iteration, according to which $89 \%$ of the total heat generated falls on the wheel side and $11 \%$ to the brake block side. As a result of this heat partition, the temperature of the two surfaces in friction is identical with proper approximation. In case of a transient calculation, the measures of heat partition are a bit different at each time step, for example ate the beginning of the simulation the $86 \%$ of the total heat power acted on the wheel and $14 \%$ on the brake block. 


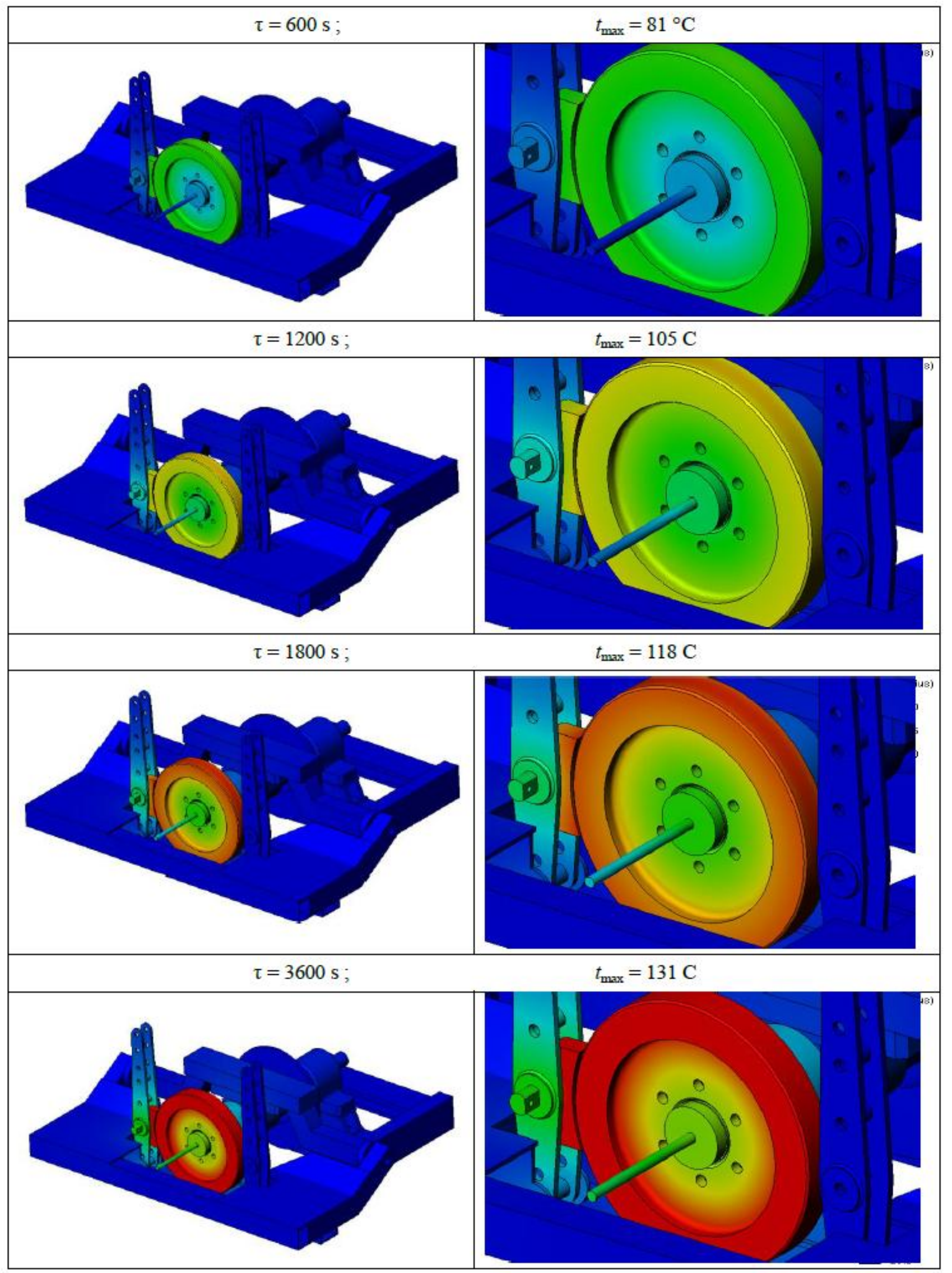

Fig. 13. Temperature distribution of the entire model and the immediate surroundings of the brake block and the wheel at discrete moments of time 
Control point 1.

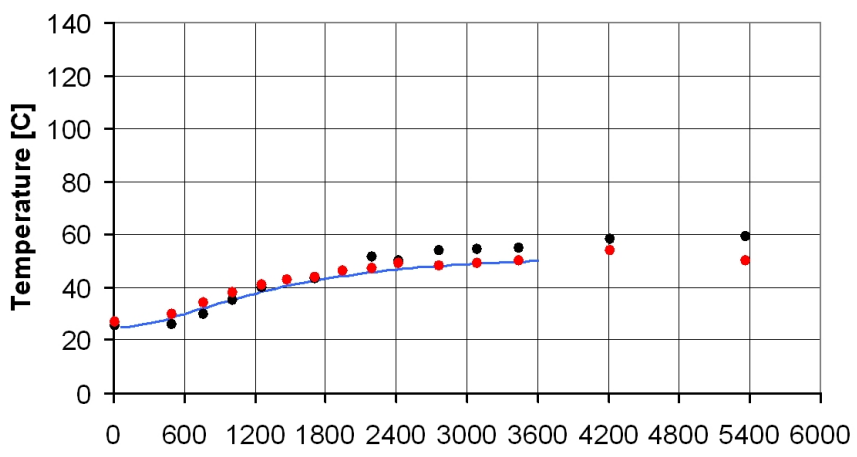

Time [s]

- Laser measurement - Thermometer measurement - FE calculation Control point 2.

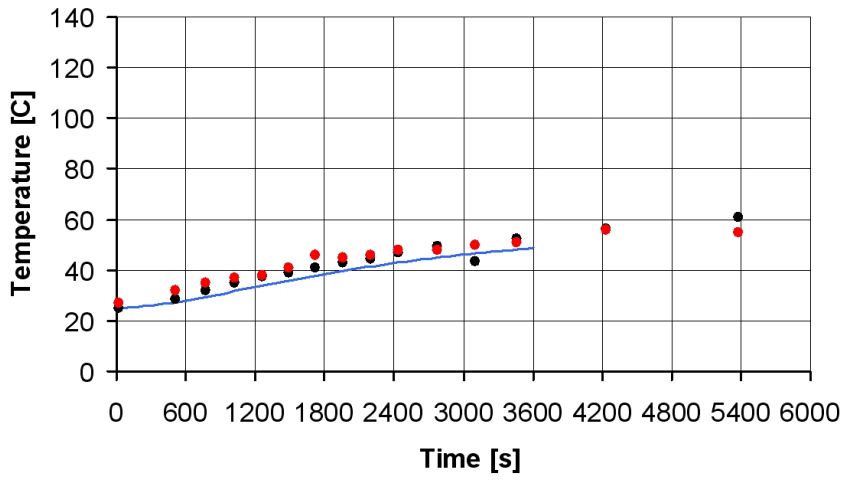

- Laser measurement - Thermometer measurement — FE calculation

Fig. 14. Measurement and calculation results at measured points 1 and 2

Transient heat partitions were specified with iteration in every 60 seconds in the transient simulations in order to fulfil the condition of Block [4]. Fig.12 shows the temperature of the surfaces in friction of the wheel and the brake block. The Figure indicates that the temperature of the brake block and the wheel practically coincide, evidencing the correct proportions of distributing the heat generated.

Fig. 12 shows the thermal distribution of the entire model and the small environment of the brake block and the wheel at given moments of time. In order to illustrate the temperature development the temperature values was presented according to the same temperature chart at each moment, i.e. the maximum temperature was set to $120^{\circ} \mathrm{C}$ in Fig. 12 .

7 Comparison of measurement and calculation results

In the test, the measurement configuration contained 1 brake block where the load was $100 \mathrm{~N}$, the rpm of the wheel was 913 , and the environment temperature was $25^{\circ} \mathrm{C}$. At the designated places of measurement (Tab. 3, temperatures were measured by two types of thermometers (Brenner type Thermo Control laser temperature, TM-25 type Thermometer). In the course of the measurement, both thermometers were used for measurements at each measurement location (8 measured points). Obviously, only laser measurements could be applied at point 4 on the braked wheel. It can be stated in general that the contact thermometer measured $2-3^{\circ} \mathrm{C}$ lower temperatures than the laser one.
Control point 3.

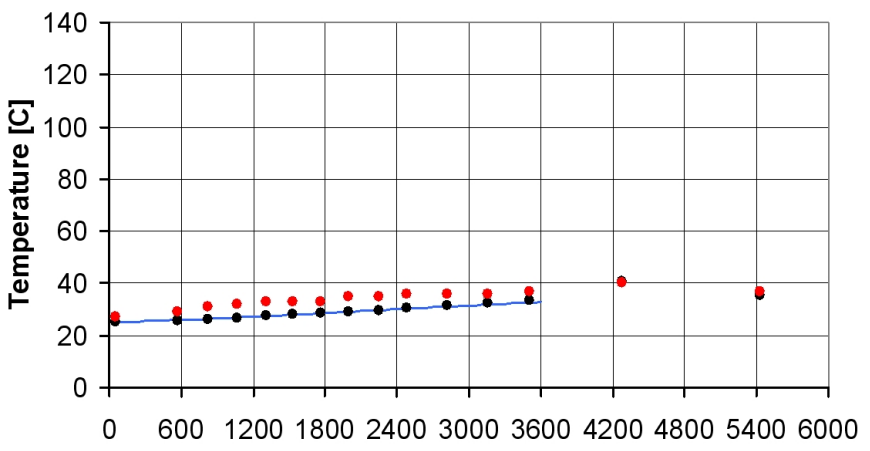

Time [s]

- Laser measurement - Thermometer measurement —FE calculation Control point 4.

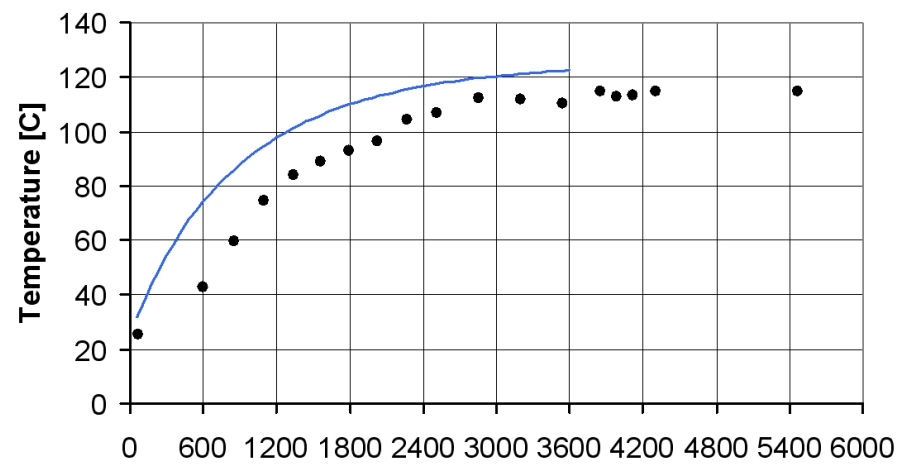

Time [s]

- Laser measurement —FE calculation

Fig. 15. Measurement and calculation results at measured points 3 and 4

Likely reasons for this include the thermal contact resistance between the tip of the thermometer and the surface as well as the thermal inertia of the sensor. The comparison of the measured and calculated temperature values are shown in Figs.14-17.

Unfortunately, the contact temperature can not be measured directly. Control points 5 and 6 are near the contact surfaces illustrated the heat generation in the vicinity of the contact area (see Fig.11 and Fig.16. These measured and calculated temperature values are in good agreement near the contact area.

\section{Conclusion}

Based on simulations using the 3D transient thermal FE model of the equipment to simulate a complete brake block and wheel connection, it can be stated that in the course of the braking process, the measurement and calculation results coincide in their characteristics, with temperature values varying at certain parts of the equipment. The nature of the different temperatures calculated and measured on the braked wheel (point 4) are similar: measured values are systematically lower - by $10{ }^{\circ} \mathrm{C}$ - than those calculated. The presumable reason for this can be that laser temperature measurements were performed on moving surfaces, which is "not recommended" according to the operating manual of the instrument. A common characteristic feature of the places of measurement on the platform part is that calculated temperatures are lower than those measured. This may be 
Control point 5.

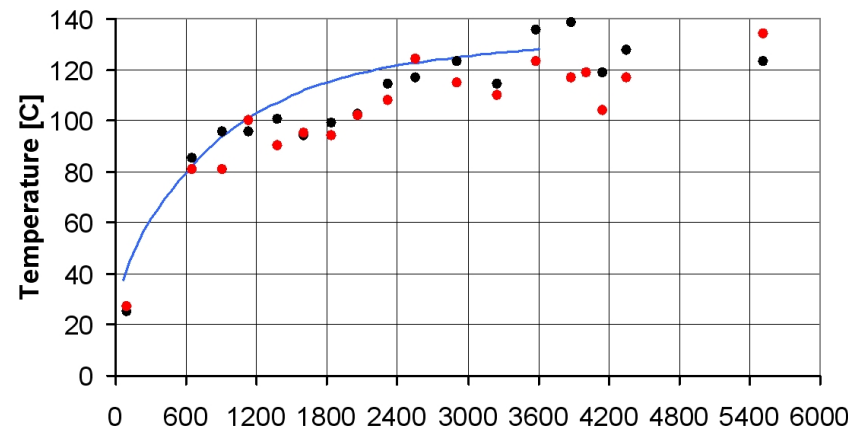

Time [s]

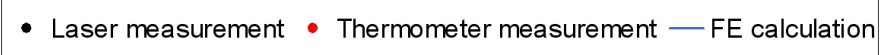
Control point 6.

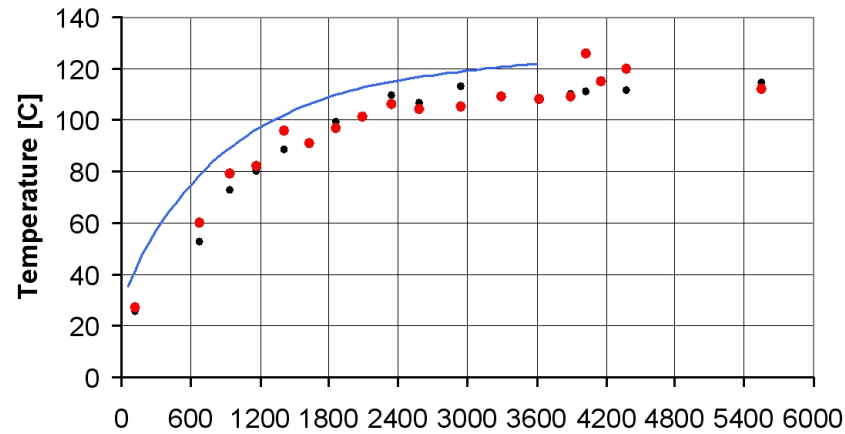

Time [s]

- Laser measurement - Thermometer measurement — FE calculation

Fig. 16. Measurement and calculation results at measured points 5 and 6

due to the fact that the ball bearings built in the test equipment act as heat sources themselves at the tested rpm, and this must be taken into consideration in the calculation model as well.
Control point 7 .

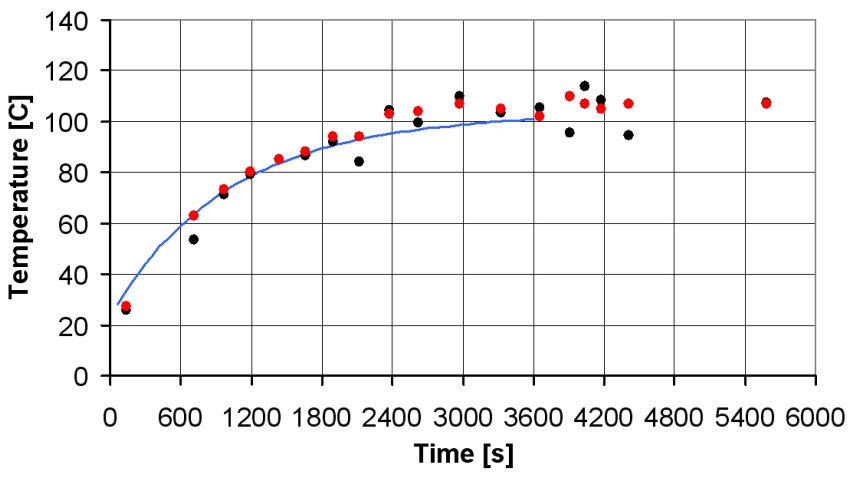

- Laser measurement - Thermometer measurement —FE calculation Control point 8.

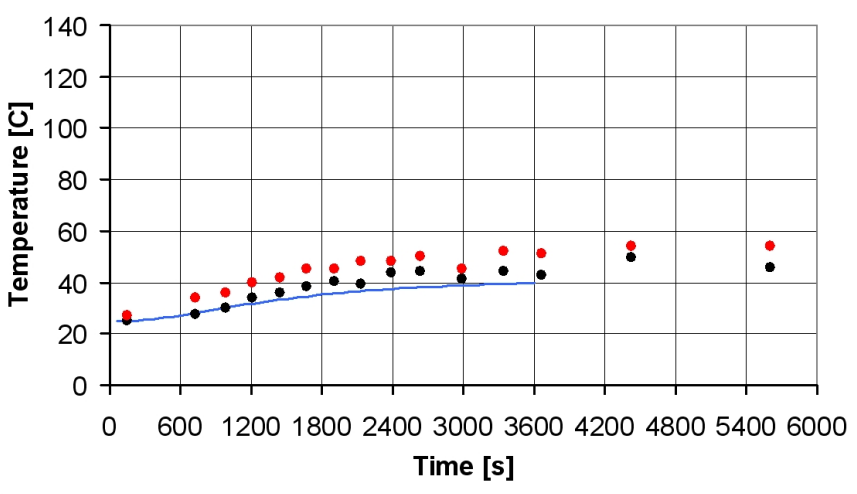

- Laser measurement - Thermometer measurement — FE calculation

Fig. 17. Measurement and calculation results at measured points 7 and 8

\section{References}

1 Vernersson $\mathbf{T}$, Thermally induced roughness of tread-braked railway wheels Part 1: modelling and field measurements, Wear, 221(2), (2007), 106-116, DOI 10.1243/0954409JRRT57

2 Bharat Bhushan: Modern Tribology Handbook, Two Volume Set (2000).

3 Warren M, Rohsenow J, Hartnett, Young I. Cho, Handbook of Heat, Third Edition, (McGraw-Hill), 1998.

4 Blok H, The Flash Temperature Concept, Wear, 6(6), (1963), 483-493, DOI 10.1016/0043-16486390283-7

5 Kónya L, PEEK / acél csúszó pár kopásának szimulációja a höfejlődés figyelembevételével, Ph.D. thesis, (2005). 